\title{
Safe-Sex Knowledge, Self-Assessed HIV Risk, and Sexual Behaviour of Young Portuguese Women
}

\author{
Eleonora C.V. Costa ${ }^{a}, b$ Teresa McIntyre ${ }^{c}$ Domingos Ferreira ${ }^{b}$ \\ ${ }^{a}$ North Regional Health Administration, ACES Cávado III - Barcelos/Esposende, Barcelos/Esposende, Portugal; \\ ${ }^{b}$ Department of Psychology, Portuguese Catholic University, Braga, Portugal; ' $T$ Texas Institute for Measurement, \\ Evaluation and Statistics and Department of Psychology, University of Houston, Houston, TX, USA
}

\section{Keywords}

HIV · Portuguese women · Safe-sex knowledge $\cdot$ Risk perception $\cdot$ Sexual behaviour

\begin{abstract}
Background: Young women make up most cases of HIV infection in Portugal (e.g., 26\% in 2012), but their sexual behaviour, ability to recognize sexually transmitted disease (STD) risk in partners, and knowledge and practice of safe sex are underresearched. Methods: We studied these issues in a group of 177 women from Northern Portugal, together with their social, educational, and religious background. The women filled out several self-report questionnaires developed in the USA that have been adapted and validated for use in Portugal. They assess HIV knowledge, risk perception, and sexual risk behaviour. Results: We documented good knowledge about HIV transmission and prevention, although there are still some myths; $79.9 \%$ of the women knew that condoms prevent HIV transmission, but only $46 \%$ of them declared to use them regularly. Thus, knowledge does not imply adequate preventive behaviour. Women lacking higher education had poorer knowledge of HIV biology and of partner HIV risk. Despite being aware of HIV cases
\end{abstract}

in their communities, most women deemed themselves at little risk, especially those lacking higher education, with many arguing that monogamy protects them, and, importantly, many preferring to ignore their partners' current and past behaviour when assessing their exposure. Conclusion: These results point to important intervention targets for campaigns to curb STD infections among young women.

๑ 2018 The Author(s). Published by S. Karger AG, Basel on behalf of NOVA National School of Public Health

\section{Conhecimento sobre o VIH, perceção de risco para - VIH e comportamento sexual de jovens mulheres portuguesas}

\section{Palavras chave}

$\mathrm{VIH}$ - Mulheres portuguesas - Conhecimentos sobre o VIH . Percepção de risco $\cdot$ Comportamento sexual

\section{Resumo}

Antecedentes: As mulheres jovens constituem a maioria das infeções por VIH em Portugal (por exemplo, 26\% em 2012), mas o seu comportamento sexual, a capacidade de

\section{KARGER}

E-Mail karger@karger.com www.karger.com/pjp

Karger Open access (c) 2018 The Author(s) Published by S. Karger AG, Basel on behalf of NOVA National School of Public Health

This article is licensed under the Creative Commons AttributionNonCommercial-NoDerivatives 4.0 International License (CC BYNC-ND) (http://www.karger.com/Services/OpenAccessLicense) Usage and distribution for commercial purposes as well as any distribution of modified material requires written permission.
Eleonora C.V. Costa

North Regional Health Administration, ACES Cávado III - Barcelos/Esposende Department of Psychology, Portuguese Catholic University PT-4700 Braga (Portugal)

E-Mail eleonora.costa@ arsnorte.min-saude.pt or eleonora@braga.ucp.pt 
reconhecer o risco de IST em parceiros e o conhecimento e a prática de sexo seguro são pouco investigados. Métodos: Estudaram-se essas questões num grupo de 177 mulheres do Norte de Portugal, juntamente com seus antecedentes sociais, educacionais e religiosos. As mulheres em estudo preencheram vários questionários de auto relato desenvolvidos nos Estados Unidos da América e que foram adaptados e validados para uso em Portugal. Foi avaliado o conhecimento sobre o $\mathrm{VIH}$, a perceção de risco e o comportamento sexual de risco. Resultados: Documentaram-se bons conhecimentos sobre a transmissão e a prevenção do $\mathrm{VIH}$, embora haja alguns mitos; $79,9 \%$ das mulheres sabem que os preservativos impedem a transmissão do $\mathrm{VIH}$, mas apenas $46 \%$ declara usá-los regularmente. O conhecimento não implica o comportamento preventivo adequado. As mulheres que não possuíam escolaridade de nível superior tinham um conhecimento mais pobre no que se refere à biologia do $\mathrm{VIH}$ e ao risco de VIH no parceiro. Apesar de estarem cientes dos casos de VIH em suas comunidades, a maioria das mulheres considerou-se com pouco risco, especialmente aquelas que não possuem ensino superior, argumentando que a monogamia as protege e, principalmente, muitas preferem ignorar o comportamento atual e passado de seus parceiros ao avaliar a sua exposição. Conclusão: Os resultados identificam importantes alvos de intervenção para as campanhas de prevenção de ISTs na população feminina.

(c) 2018 The Author(s). Published by S. Karger AG, Basel on behalf of NOVA National School of Public Health

\section{Introduction}

HIV/AIDS is a worldwide epidemic and has affected 1.6 million people who inject drugs [1]. In Europe, about 2.2 million people were living with HIV in 2012 [2]. Joint United Nations Program in HIV/AIDS (UNAIDS) and WHO estimates indicate that in that year, about 48,000 people in Portugal were living with HIV $[2,3]$. These cases were associated with sexual transmission in heterosexual couples (63.1\%) and homosexual men (24.1\%), and in $10 \%$ of the new cases, the transmission was related to drug use according to the estimates of the National Health Institute Doutor Ricardo Jorge [4].

In Portugal, a large percentage of those affected by sexually transmitted diseases (STDs) are women. At present, women account for $26 \%$ of all AIDS cases reported to the Health Ministry [4]. This percentage is expected to rise due to the fact that women have accounted for more than $30 \%$ of newly diagnosed HIV cases in the last 5 years [4].
However, few studies have investigated the factors increasing the vulnerability to HIV and other STDs among Portuguese women, although this would help improve STD prevention efforts. Similarly, several measures have been taken to curb HIV infections, such as promoting safe sex and improving knowledge of HIV transmission, vulnerability to HIV, and HIV risk factors in partners, but only few studies have examined their effectiveness [5]. These interventions have been mainly educational and skill trainings.

Epidemiological studies show that Portuguese women between the ages of 20 and 44 years are the fastest-growing group becoming infected with HIV [4]. The main mode of HIV transmission in this group is through unprotected heterosexual sex with infected partners [4]. HIV infection rates are declining in most age groups worldwide, but the infection rates among young adults are unchanged or increasing [6].

Young adults are at increased risk of HIV infection because of their high sex drive, high probability of spontaneous sexual encounters, and limited knowledge of HIV biology and of the factors indicating partner risk. Young single women, in particular, are uniquely at risk in many respects [7-11]. They are less likely to use condoms and more likely to have multiple sexual partners (and become infected with STDs), and are less assertive when requesting and enforcing condom use [12, 13]. Furthermore, women might downplay their risk of HIV in order to avoid dealing with partner infidelity and risking alienating partners with safe-sex requests $[14,15]$. Some studies show that even women who know they are at risk do not use condoms regularly [16].

Sociocultural factors also seem to play a significant role in women's sexual behaviour [17]. Some religious institutions may hinder women's knowledge of HIV and STDs, promoting opposition to sexual and STD education, which may prevent women from exposure to information about HIV and STDs and their motivation to use condoms [18]. Some institutions also ban contraceptives, indirectly promoting risky sexual practices, which prevents conception and preserves virginity but is more favourable to HIV transmission. Among Latin women, fertility plays a major role in both female identity and social acceptance, and this too makes condom use less likely. Similar to Afro-American and Hispanic women, Portuguese women tend to be more religious and to conform to traditional and conservative gender roles that prescribe submissiveness. Studies have shown that extramarital sex is less likely among women than among men [19] and that a woman's adherence to a submissive gender role can 
increase her HIV risk [20]. In fact, sexual communication and negotiation are hindered by gender-conforming "dominant" and "submissive" posturing by either partner [21].

Relationship dynamics and skills are also important in determining adherence to safe-sex practices. Lack of communication and negotiation between partners is a main predictor of STD risk among young adults. Studies have shown that condom use is less likely when sexual communication is poor [22]. Alcohol and substance abuse increase the HIV risk as well, since they make unsafe sexual behaviour more likely [6], especially among women who would otherwise practice safe sex [23]. Poor sexual negotiation skills, alcohol and drug abuse, multiple sexual partners, early sexual initiation, unprotected sex, and inconsistent condom use are sexual practices that put gregarious adolescents and young adults at an especially high risk of HIV infection and STDs [6].

Efforts to protect women from HIV and to design health policies and screening services specifically for them require detailed information about their knowledge of HIV, their perception of HIV and STD risk factors, their sexual behaviour, and their STD risk management, as well as about their attitudes towards HIV education and prevention and their adherence to safe-sex practices [24].

Although there is now solid general knowledge of the risk factors for STDs and HIV, there is a lack of knowledge that is specific to women, young women in particular [1]. In Portugal this knowledge is particularly needed in order to shape policy and prevention efforts, but generally the necessary research has not been carried out.

We consider the evaluation of variables included in social cognitive theory and in health belief models important for risk behaviour change with regard to HIV, such AIDS knowledge, perceived vulnerability, and sociodemographic factors, and they can also interfere with individual perceptions and affect behaviour in an indirect way $[25,26]$.

This paper aims to characterize the STD risk profile of young Portuguese women in order to help inform intervention goals and their implementation. The psychosocial risk factors considered here are the following: (1) knowledge of HIV/AIDS biology and HIV transmission; (2) knowledge of HIV prevention; (3) personal assessment of HIV risk in one's community and potential partners, and of the personal risk of becoming infected; (4) adherence to safe-sex practices, especially condom use; and (5) current and past sexual activity. The study also investigated the relationship between condom use and the social, educational, and religious background, which should also help orient and implement anti-STD campaigns.

\section{Methods}

\section{Ethics Statement}

This research involved human participants, and for this reason informed consent was obtained. All clinical investigations were conducted according to the principles expressed in the Declaration of Helsinki. Approval was obtained from the institutional review board at Minho University, and the participants provided written consent to participate in this study; the ethics committee approved this consent procedure, although the data were analysed anonymously. In regard to participants younger than 18 years, consent from their parents/guardian was obtained, and the ethics committee approved this consent procedure as well.

\section{Participants and Procedure}

The study participants were 177 women at risk of HIV/STD infection who were recruited at the Youth Institute in Northern Portugal, a primary healthcare centre in Northern Portugal. The women were there to take advantage of a free "youth sexuality consultation" offered by the Portuguese Ministry of Health. The selection criteria were the following: (1) concern regarding a possible STD; (2) having had more than one sexual partner in the previous 6 months; (3) having had a partner who had had other sexual partners in the previous 6 months; or (4) having a partner known to have used intravenous drugs. The subjects' age ranged from 16 to 26 years $(M=20.0, S D=2.3)$. Forty percent had less than a high-school education and $60 \%$ had some college education. Ninety-five percent of the women were Portuguese Caucasian and 5\% were Africa-born Blacks. One percent of the women were married. Most of them lived with their parents (61\%), 11\% with more distant relatives, $17.5 \%$ with friends, $10 \%$ alone, and only $5 \%$ with their current sexual partner. No one lived with children or was pregnant, but $1 \%$ had had children and $3.5 \%$ had been pregnant at least once. Fourteen percent had a paying job and $91 \%$ had a yearly income below EUR 3,000. A considerable part of them defined themselves as very religious (48.5\%), $40 \%$ as somewhat religious, and $11.5 \%$ as not religious at all. Of the religious participants, $91 \%$ were catholic, of whom $51 \%$ reported being practicing Catholics.

The participants were recruited during a youth sexuality consultation. This free youth consultation is a collaboration between the Youth Institute and the Regional Health Centres. Women between 16 and 29 years old were considered if they had at least 4 years of education and were at risk of HIV as defined by the criteria above, which was verified during the recruitment procedure. Participants younger than 18 years obtained parental permission. Upon informed and voluntary consent, the women answered the questionnaire package in a designated private area.

\section{Measures}

The women filled out several self-report questionnaires developed in Anglo-Saxon countries that have been adapted and validated for use in Portugal. These questionnaires assess HIV knowl-
18

Port J Public Health 2018;36:16-25 DOI: $10.1159 / 000486466$
Costa/McIntyre/Ferreira 
edge, risk perception, and sexual risk behaviour. The evaluated measures and their psychometric properties in this sample are described below.

Safe-Sex Knowledge. This was assessed by 14 questions that were taken from the 1988 Public Health Service AIDS Information Survey [27-29] and subsequently translated, adapted, and validated for use in Portugal [30]. They assess one's knowledge of HIV transmission and prevention, and have been shown to measure safe-sex knowledge accurately [8]. The items have a 3-option response format: "wrong," "right," and "don't know." The percentage of correct answers was used as a summary score. The Cronbach a internal-consistency reliability for the 14-item scores was high $(\alpha=0.89)$. Eight of the 14 items measure knowledge of HIV transmission, and they produced a Cronbach $\alpha$ of 0.82 . Six items assess the knowledge of how to prevent HIV transmission during sexual activities (Cronbach $\alpha=0.83$ ).

Self-Reported Sexual Risk Behaviour. This was assessed by several items from the Women's Health Study [29] that have been translated and adapted for use in Portugal [30]. Condom use items ask participants to report their sexual behaviour and condom use during oral, anal, and vaginal sex over the last 2 weeks, the last 2 months, and the last 6 months (e.g., "During the past two weeks, how many times did you engage in oral sex?"; "Of these times, on how many occasions did you use a condom?"). Additionally, the women reported the number of their partners over the past 2 weeks and over the past 2 and 6 months, as well as if - and how many times - they had traded sex for money or drugs during the same periods (e.g., "During the past two weeks, with how many people have you had sex?"; "During the past two weeks, how many times have you traded sex for money or drugs?"). Finally, the women also reported their condom use in the last 4 sexual acts, their intention to purchase condoms in the near future, and whether they had purchased condoms recently. The response format was a 4-point Likert scale ("no," "occasionally," "frequently," and "always or almost always") [29].

Perceived Risk. Two items assessed whether the participants' heterosexual contacts in general, and their sexual behaviour in particular, placed them at risk of HIV infection. These items were adapted for use in Portugal from the Women's Health Study [9, 31]. A question asked whether the women discussed HIV/AIDS danger and prevention with her partners, with the response format being a 4-point Likert scale (0-3: "seldom," "never," "with some but not all partners," and "with every partner"). Four additional questions evaluated how the women assessed HIV risk in sexual partners on a 4-point Likert scale (0-3: "no," "maybe," "not sure," "yes"). The questions were: "Do you think your sexual partner(s): (a) have used I.V. drugs in the past year (injection with a needle)? (b) had other sexual partners in the past year? (c) were in prison over the past 5 years? (d) had sex with men in the past 5 years?" This measure is not meant to assess risk per se (although it has been found to be highly correlated with risk), but rather each woman's sophistication in assessing the STD risk represented by actual and potential partners. Higher scores indicate greater sophistication [31]. The Cronbach a internal-consistency reliability was not mentioned in previous studies. In our sample, a was 0.57 .

Data Analysis

Descriptive analyses of the demographic, sexual risk behaviour, safer-sex knowledge, and risk perception variables were performed. Mean (M) and SD were used to describe continuous vari-
Table 1. Unsafe sexual behaviour in the previous 2 weeks, 2 months, and 6 months

\begin{tabular}{|c|c|c|c|}
\hline \multirow[t]{2}{*}{ Measure } & \multicolumn{3}{|c|}{ Subjects, \% } \\
\hline & 2 weeks & 2 months & 6 months \\
\hline \multicolumn{4}{|c|}{ Vaginal intercourse } \\
\hline None & 21.5 & 9 & 4 \\
\hline $1-5$ times & 59.3 & 20.8 & 12.5 \\
\hline$>5$ times & 19.2 & 70.2 & 83.5 \\
\hline \multicolumn{4}{|l|}{ Fellatio } \\
\hline None & 68.4 & 52 & 46.9 \\
\hline $1-5$ times & 28.8 & 26.4 & 14.8 \\
\hline$>5$ times & 2.8 & 21.6 & 38.3 \\
\hline \multicolumn{4}{|l|}{ Anal sex } \\
\hline None & 96.6 & 92.6 & 87.6 \\
\hline $1-5$ times & 2.9 & 6.2 & 9.1 \\
\hline$>5$ times & 0.5 & 1.2 & 3.3 \\
\hline \multicolumn{4}{|c|}{ With how many people } \\
\hline None & 20.9 & 10.2 & 3.4 \\
\hline 1 partner & 79.1 & 87 & 88.1 \\
\hline$>1$ partner & 0 & 2.8 & 8.5 \\
\hline \multicolumn{4}{|c|}{ Exchange of sex for money or drugs } \\
\hline None & 98.8 & 98.9 & 98.9 \\
\hline 1 time & 0.6 & 0.6 & 0.6 \\
\hline$>1$ time & 0.6 & 0.6 & 0.6 \\
\hline
\end{tabular}

ables. Categorical variables were described as absolute frequencies and relative frequencies. Furthermore, the Mann-Whitney U test (for continuous variables) and the $\chi^{2}$ test (for categorical variables) were conducted to compare women having or undergoing higher education with those without any higher education, practicing Catholics with non-practicing Catholics, adult with adolescent women, as well as comparing the women regarding their sexual risk behaviour, safer-sex knowledge, and concern about unsafe sexual activities and with personal exposure.

\section{Results}

\section{Sexual Risk Behaviour}

The results regarding self-reported sexual activity and safe-sex behaviour are presented in Tables 1-3. All women reported being sexually active, with $59.3 \%$ reporting vaginal intercourse at least once in the last 2 weeks and $83.5 \%$ reporting 5 or more events during the last 6 months. Only 14.8 and $9.1 \%$ reported having engaged in fellatio or anal sex in the previous 6 months. In all, $88.1 \%$ reported having had a single partner during the same period, and none reported having exchanged sex for money or drugs. The rate of abstinence during 6 months was low (3.4\%). Condom use was inconsistent, with $54.8 \%$ reporting un- 
Table 2. Condom use during vaginal, oral, or anal intercourse in the previous 2 weeks, 2 months, and 6 months

\begin{tabular}{llll}
\hline Condom use & \multicolumn{2}{l}{ Subjects, $\%$} & \\
\cline { 2 - 4 } & 2 weeks & 2 months & 6 months \\
\hline Vaginal intercourse & & 39 & \\
$\quad$ None & 54.8 & 24.2 & 20.5 \\
$1-5$ times & 37.8 & 36.8 & 53.5 \\
$>5$ times & 7.4 & 93.2 & 89.3 \\
Fellatio & & 5.6 & 5.7 \\
$\quad$ None & 96 & 1.2 & 5 \\
$1-5$ times & 4 & & \\
$>5$ times & 0 & 96 & 92.7 \\
Anal sex & & 3.5 & 6.2 \\
None & 97.2 & 0.5 & 1.1 \\
$1-5$ times & 2.8 & & \\
$>5$ times & 0 & & \\
\hline
\end{tabular}

protected vaginal intercourse in the previous 2 weeks, and 96 and $97.2 \%$ reporting at least 1 event of unprotected fellatio and/or anal sex over the same period, respectively, albeit the latter two activities were infrequent ( 28.8 and $2.9 \%$ of the subjects reported either or both in the last 2 weeks). The reports of unsafe sex over the previous 2 weeks were consistent with those over the last 6 months, even though the last-6-month estimates tended to be lower for unprotected vaginal intercourse (26 vs. $39 \%$ ), unprotected fellatio (89.3 vs. $93.2 \%$ ), and anal sex (92.7 vs. $96 \%)$. Regarding condom use in the last 4 sexual acts, nearly half of the women reported not having used condoms at all (41.2\%) and 13\% reported not having used them every time. Regarding proactive condom procurement, $48.6 \%$ reported never buying or procuring free condoms before intercourse and $37.9 \%$ declared not intending to procure them in the future. However, 16.4, 23.7, and $41.8 \%$ reported that their partners had been bringing condoms occasionally, frequently, and always, respectively.

\section{Characterizing Young Women's Risk Profiles}

The sociocultural profiles of women at the highest STD risk who should be targeted by STD prevention campaigns are described below. We contrasted (a) women with higher education with those without higher education, (b) women who professed being practicing Catholics with those who did not, and (c) adult with adolescent women. Contrasts were made regarding safe-sex behaviour and knowledge, as well as regarding HIV knowledge and HIV risk management. We expected
Table 3. Safe-sex behaviour of the Portuguese women

\begin{tabular}{ll}
\hline Measure & Subjects, \% \\
\hline Condom use in the last 4 sexual acts & \\
$\quad$ None & 41.2 \\
1-2 times & 13 \\
>2 times & 45.8 \\
Bought or got condoms & \\
No & 48.6 \\
Occasionally & 19.8 \\
Frequently & 15.8 \\
Always & 15.8 \\
Intention to buy or get condoms & 37.9 \\
No & 24.9 \\
Occasionally & 16.4 \\
Frequently & 20.9 \\
Always & \\
Trust in partner to bring condoms & 18.1 \\
No & 16.4 \\
Occasionally & 23.7 \\
Frequently & 41.8 \\
Always & \\
\hline
\end{tabular}

women with higher education to practice safe sex more frequently, since they should have better STD knowledge. We expected practicing Catholics to use condoms less, since their religion restricts their use. Also, we expected adults to practice safe sex more systematically, since a longer life experience and better-developed selfassurance should enable them to request and enforce condom use better.

Since the exploratory analysis revealed a pervasive lack of normality, we used non-parametric significance tests but did not attempt correcting for multiple testing. Therefore, the presented statistical significances have only a heuristic value.

Women Having or Undergoing Higher Education versus Those with No Higher Education

Previous-2-Week Reports. After subdividing the subjects according to their having (or undergoing) higher education or not, we looked for differences in unsafe-sex behaviour. We found that the subjects with no higher education reported having engaged more frequently in fellatio without condom use $(\mathrm{M}=5.23$ vs. $4.69 ; Z=-2.752$; $p=0.006$; Mann-Whitney U test).

Previous-6-Month Reports. The women with no higher education reported more frequent condom usage during vaginal intercourse $(\mathrm{M}=19.6$ vs. $32.1 ; Z=-2.009 ; p=$ $0.045)$. Additionally, the women with higher education 


\begin{tabular}{lr}
\hline Question & $\%$ co \\
\hline Can someone be infected with HIV by... & \\
...working near someone with HIV? & 80.9 \\
...eating at a restaurant in which the cook has HIV? & 74.2 \\
...shaking hands, touch, or kiss the face of someone with HIV? & 79.9 \\
...sharing plates, forks, or glasses with someone with HIV? & 69.1 \\
...using public bathrooms? & 53.1 \\
...sharing syringes with someone with HIV? & 79.9 \\
...being coughed or sneezed at by someone with HIV? & 57.7 \\
...mosquitoes or other insects infected with HIV? & 30.9
\end{tabular}

Table 5. Knowledge of HIV prevention

\begin{tabular}{ll}
\hline Question & \% correct \\
\hline Effective methods for avoiding AIDS: & \\
Have no sexual relationship & 46.9 \\
Use a condom & 79.9 \\
Use a diaphragm & 60.3 \\
Use only gel, foam, or spermicidal cream & 74.7 \\
Interrupted coitus & 76.3 \\
Have sexual intercourse with only one & \\
$\quad$ partner without HIV & 53.1 \\
\hline
\end{tabular}

reported more fellatio without condom use $(\mathrm{M}=14.7 \mathrm{vs}$. $11.8 ; Z=-2.613 ; p=0.009)$. However, the women with no higher education reported more frequent use of condoms over the last 4 sexual acts $(M=3.02$ vs. $2.15 ; Z=-2.823$; $p=0.005)$. There were no other differences.

Practicing Catholics versus Non-Practicing Catholics

Previous-2-Week Reports. The practicing catholic women reported having used condoms during anal sex more often than did the non-practicing ones $(\mathrm{M}=0.023$ vs. $0.000 ; Z=-2.016 ; p=0.044)$.

Previous-2-Month Reports. The non-practicing catholic women reported more frequent anal sex $(\mathrm{M}=0.529 \mathrm{vs}$. $0.253 ; Z=-2.730 ; p=0.006$ ).

Previous-6-Month Reports. The non-practicing catholic women reported having brought condoms to intercourse events more often $(\mathrm{M}=1.29$ vs. $1.02 ; Z=-2.030$; $p=0.042)$. There were no other differences.

Adult versus Adolescent Women ( $>18$ vs. $\leq 18$ Years)

Previous-2-Week Reports. The adult women reported having engaged more often in fellatio than the adolescents $(\mathrm{M}=1.28$ vs. $1.04 ; Z=-3.194 ; p=0.001)$.
Previous-2-Month Reports. The adult women reported having engaged more often in fellatio $(\mathrm{M}=5.41$ vs. 3.84; $Z=-3.880 ; p=0.000$ ).

Previous-6-Month Reports. The adult women reported having engaged more often in fellatio $(\mathrm{M}=15.5$ vs. 9.33; $Z=-3.636 ; p=0.000$ ), and the adolescent ones reported more frequent condom use (over the last 4 sexual acts; $M=3.07$ vs. $2.18 ; Z=-2.671 ; p=0.008)$. No other differences were found.

\section{Safer-Sex Knowledge}

Tables 4 and 5 summarize the women's knowledge of HIV transmission. It was generally good, with most women knowing that sharing used hypodermic needles entails a high HIV risk, although a significant number of the women did not know about the transmission risk of sharing toilets and kitchen utensils, as well as from being coughed or sneezed at by HIV-infected people. Knowledge of HIV prevention was also good, with 79.9\% knowing that condoms provide very effective prevention, but most of the women did not know that abstinence is very effective prevention.

Women Having or Undergoing Higher Education versus Those with No Higher Education

The women with higher education knew better than those lacking it that HIV transmission through coughing or sneezing is unlikely ( $\mathrm{M}=0.963$ vs. $0.908 ; Z=-2.371$; $p=0.018$ ), and also that diaphragms offer no protection ( $\mathrm{M}=0.935$ vs. $0.923 ; Z=-2.379 ; p=0.017)$. No further marked differences were found, and therefore the subjects with higher education had only slightly better knowledge of HIV transmission and prevention. This shows that anti-HIV campaigns are failing to reach even bettereducated women. 
Table 6. Concern about personal risk and risk entailed by partners

\begin{tabular}{|c|c|}
\hline Question & Subjects, \% \\
\hline \multicolumn{2}{|c|}{ I believe sexual contact between a man and women has... } \\
\hline ...no risk & 2.3 \\
\hline .... a low risk & 5.1 \\
\hline ...a moderate risk & 44.6 \\
\hline .... high risk & 48 \\
\hline \multicolumn{2}{|l|}{ I believe my current sexual behavior has... } \\
\hline ...no risk & 56.5 \\
\hline ...a low risk & 38.4 \\
\hline ...a moderate risk & 4 \\
\hline .... high risk & 1.1 \\
\hline \multicolumn{2}{|l|}{ I speak about AIDS and about its prevention... } \\
\hline ...with all my partners & 71.8 \\
\hline ...with some partners but not others & 18.1 \\
\hline ...rarely or never & 10.2 \\
\hline \multicolumn{2}{|l|}{ I think that some of my sexual partners... } \\
\hline ...have used injectable drugs at some time & 2.8 \\
\hline ...had other sexual partners last year & 31.1 \\
\hline ...were in prison during the last 5 years & 0 \\
\hline $\begin{array}{l}\text {...had sexual relations with other men in the } \\
\text { last } 5 \text { years }\end{array}$ & 0.6 \\
\hline
\end{tabular}

Practicing Catholics versus Non-Practicing Catholics No marked differences between the practicing and non-practicing catholic women were found with respect to knowledge of HIV transmission and prevention. This contrasts with the fact that the catholic women reported using condoms more frequently.

Adult versus Adolescent Women ( $>18$ vs. $\leq 18$ Years)

The adult women knew better than the adolescent ones that HIV risk from public bathrooms is negligible $(\mathrm{M}=0.931$ vs. $0.842 ; Z=-2.657 ; p=0.008)$ and that diaphragms do not prevent HIV transmission ( $\mathrm{M}=0.948$ vs. $0.895 ; Z=-2.602 ; p=0.009)$. There were no additional differences. Note that these two subsamples are not identical to those created according to higher education: there were 143 adult women ( $71.5 \%$ of all women), of whom $124(86.7 \%)$ had higher education, while there were 57 adolescents $(28.5 \%$ of the total), of whom only $5(8.8 \%)$ had higher education.

\section{Concern about Unsafe Sexual Activities and about \\ Personal Exposure}

Table 6 summarizes the concerns about personal exposure to STD/HIV and with the risk entailed by the partners. In all, $44.6 \%$ of the subjects thought that heterosexual contact entails an only moderate HIV risk, while $48 \%$ deemed it high. Therefore, about half of our subjects still assumed that HIV/AIDS affected mainly homosexuals. The majority (56.5\%) considered themselves not to be at risk. Most subjects declared that they were concerned about HIV, and $71.8 \%$ reported discussing HIV/AIDS regularly with their partners. Additionally, the participants reported that over the last 5 years, their partners had not used injectable drugs, had not been in prison, and had not had sex with men. However, $31.1 \%$ suspected their partners to have had sex with another partner in the previous year.

Women Having or Undergoing Higher Education versus Those with No Higher Education

The women with higher education assessed their HIV risk to be higher than did those lacking higher education $(\mathrm{M}=0.574$ vs. $0.492 ; Z=-1.998 ; p=0.046)$, and yet they engaged in unsafe sex with equal frequency. No other variables showed any marked differences. There were also no marked differences between the practicing and nonpracticing catholic women or between the adults and adolescents.

\section{Sociocultural Risk Profiles}

The above results suggest the following risk profiles: non-practicing catholic women, adult women, and women with higher education appear to be at high risk, since they (1) use condoms less often and (2) engage more frequently in unsafe sex, and this despite their better knowledge of HIV transmission and prevention and - in the case of those with higher education - despite estimating their own risk of HIV exposure as being high.

\section{Discussion and Conclusions}

Our results are consistent with published findings. In our sample, we found several at-risk women who had been sexually active during the past 6 months and had often engaged in moderately risky sexual behaviour (e.g., unprotected vaginal intercourse, inconsistent condom use, and negligent condom procurement). Additionally, we found good knowledge of HIV transmission and prevention (e.g., most women knew that condoms prevent HIV), although there are still some myths (e.g., most women believed that they could get HIV through mosquitoes or other insects infected with HIV). The personal risk was deemed to be low, but the HIV risk in the community was estimated to be high. Most participants did not consider their partners to be at risk, but nonetheless 
they reported discussing HIV with their partners. Most women reported serial monogamy, and very few reported having had more than one partner in the last 6 months. Full abstinence during the last 6 months was rare (reported by $3.4 \%$ of the subjects), making it an STD prevention strategy unlikely to take hold. Our subjects reported having engaged in vaginal sex clearly more frequently $(83.5 \%)$ than in anal and oral sex (3.3 and 38.3\%, respectively), which may reflect small-city sexual mores and invites comparisons with Lisbon and Oporto.

The non-practicing catholic women and also those with higher education reported more unsafe sexual behaviour (especially fellatio and anal sex) and fewer safesex behaviours like condom use than did the younger practicing Catholics and those with no higher education. Previous studies have shown that religiosity, practiced or not, is positively correlated with safe sex among women [32]. The above suggests that STD prevention campaigns should consider age, religion, and educational level. However, it is possible that adult non-practicing catholic women with higher education reported their sexual behaviour more truthfully, and that therefore many of the above differences may be due to biased reporting. Additionally, as intimated above, preventing pregnancy might explain at least in part our results concerning condom use. Previous studies have shown that older European women in stable relationships tend to use the pill, which should lower condom use among them as a side effect [33]. Future studies of STD prevention need to control for condom use for pregnancy prevention and whether knowledge about sexual matters is strongly correlated with pregnancy prevention.

Studies show that campaigns promoting condom use are more successful among people with higher education [34], highlighting the need to target men and women with lower educational levels. In our sample, the women with higher education who knew that condoms were protective tended to use them less frequently, but this might be due to the fact that these women tend to be older and have more stable relationships. Knowledge of transmission and prevention was good among the women in our sample, although a majority did not know that HIV cannot be transmitted by insect bites or mere proximity to infected people. Their good HIV prevention knowledge is inconsistent with their unsafe sexual behaviour (41.2\% did not use condoms in the last 4 sexual encounters). The relationship between safe-sex knowledge and sexual behaviour is well documented [10]. Our adult women with higher education had better knowledge of HIV transmission and prevention, but they engaged more frequently in

Safe-Sex Knowledge of Young Portuguese Women unsafe sex than did younger women with no higher education. It appears important to convince all sexually active women that avoiding pregnancy should not be their only concern, since neglecting STD prevention can have very serious consequences.

However, information is not enough to change sexual behaviour, although better knowledge about HIV transmission and safe sex increases the motivation to request condom use more assertively [7]. Indeed, motivation and assertiveness training are also crucial in this respect [7] in that teaching women how to negotiate condom use more assertively is a priority. Additionally, assertiveness training empowers women in general by increasing their selfesteem.

Many of our participants considered themselves less at risk than other members of their community despite the fact that some of them were clearly at STD risk. Studies show that women who regularly engage in unsafe sex tend to consider others more at risk than themselves [9]. These women might downplay and ignore their own risk because doing otherwise could lead to confrontation with partners and even partner loss (e.g., because of fights over partner infidelity) [8]. Our participants with higher education had better knowledge of STD risk and prevention, and they reported higher personal risks than did others, but they engaged more frequently in unsafe sex as well. Most of our participants considered that in their community, women like them were at considerable risk of HIV without deeming themselves to be especially at risk, possibly because they were monogamous and preferred to view their partners as being at a low risk. This applies even to those women who reported having been involved with men who used IV drugs or had sexual relationships with other women (2.8 and $31.1 \%$, respectively). Educating these women so they can evaluate their partner's STD risk without self-deception is therefore a major priority.

Poor knowledge of HIV/STD biology and prevention together with lowballing one's personal risk may explain why most of our participants did not use condoms. However, $72 \%$ of the women concerned about HIV/AIDS also reported discussing HIV and its prevention with their sexual partners. This means that women are open to learn more about the disease. In our sample, the women who would appear to be at the greatest risk were adults with higher education who were practicing Catholics, since $87.6 \%$ of these women did not know condoms were protective and $43 \%$ of them reported not using them. However, their actual and potential partners might be unlikely to carry HIV. All the same, this group should be targeted by HIV prevention campaigns. 
The current study has a number of limitations, namely, (1) the use of self-report questionnaires, (2) a convenience sample not selected on the basis of having an STD but recruited during a youth sexuality consultation, and (3) its cross-sectional design. In fact, our study relied on self-reporting, which can be biased by interviewees' wishes to appear responsible. In future work, we intend to introduce control questions to deal with this.

Further empirical work in other regions of the country and larger samples in the northern region appear necessary in order to attain statistical significance and better accuracy, thereby retaining or discarding the trends presented above. Young Portuguese women continue to be at risk of AIDS. Indeed, epidemiological data show that infection rates have increased steadily among these women over the last 10 years [2]. Our study suggests that these women's sexual behaviour entails a serious risk of being infected with STDs. Their low use of condoms and their tendency to underestimate their exposure to STDs threaten to result in further increases in infection rates. It is important to improve safe-sex and STD knowledge, espe- cially about HIV transmission and prevention and of how to recognize the HIV risk in partners, since all of this reduces unsafe-sex behaviour and reduces STD transmission. Our future research will address the success of campaigns to improve safe-sex knowledge and behaviour. Our findings above show that the need for these interventions and for them to succeed is urgent.

\section{Acknowledgements}

This work was supported by a grant (SFRH/BD/6386/2001) from the Portuguese Foundation of Science and Technology and also by a grant (Project ADIS/0045/03) from the National AIDS Commission, Portuguese Ministry of Health. We thank all the women that agreed to participate in this study and Prof. Marcos Antezana for kindly reviewing the article.

\section{Disclosure Statement}

The authors declare that they have no competing interests.

\section{References}

1 United Nations Office on Drugs and Crime (UNODC): World Drug Report 2013. Vienna, United Nations Publication Sales, 2013.

2 World Health Organization (WHO): Key Facts on HIV Epidemic in Portugal and Progress in 2011. Geneva, World Health Organization, 2013. http://www.euro.who.int/_data/ assets/pdf_file/0009/191088/PortugalHIVAIDS-Country-Profile-2011-revision2012-final.pdf.

3 United Nations: United Nations Program on HIV/AIDS (UNAIDS): Report for Portugal. Washington, United Nations, 2012. http:// www.unaids.org/en/regionscountries/countries/portugal/.

4 Portugal, Ministério da Saúde, Instituto Nacional de Saúde Doutor Ricardo Jorge (INSA): Infecção VIH/SIDA: a situação em Portugal a 31 de dezembro de 2013. Lisboa, Departamento de Doenças Infecciosas, Núcleo de Vigilância Laboratorial de Doenças Infecciosas, Unidade de Referência e Vigilância Laboratorial Epidemiológica, 2013.

5 Costa ECV: Avaliação da eficácia relativa de duas intervenções psicoeducativas dirigidas à prevenção do Sida e promoção da saúde em mulheres com risco para o VIH; doctoral thesis, Braga, Universidade do Minho, 2006.
6 Shiferaw Y, Alemu A, Girma A, Getahun A, Kassa A, Gashaw A, et al: Assessment of knowledge, attitude and risk behaviors towards HIV/AIDS and other sexual transmitted infection among preparatory students of Gondar town, north west Ethiopia. BMC Res Notes 2011;4:505.

7 Fisher J, Fisher W: The information-motivation-behavioral skills model; in DiClemente RJ, Crosby RA, Kegler MC (eds): Emerging Theories in Health Promotion Practice and Research: Strategies for Improving Public Health. San Francisco, Jossey Bass, 2002, pp 40-70.

8 Hobfoll SE, Jackson AP, Lavin J, Britton PJ, Sheperd JB: Safer sex knowledge, behavior, and attitudes of inner-city women. Health Psychol 1993;12:481-488.

-9 Schröder KE, Hobfoll SE, Jackson AP, Lavin $\mathrm{J}$ : Proximal and distal predictors of AIDS risk behaviours among inner-city African and European American women. J Health Psychol 2001;6:169-190.

10 Türmen T: Gender and HIV/AIDS. Int J Gynaecol Obstet 2003;82:411-418.

11 Wingood GM, DiClemente RJ: The theory of gender and power: a social structural theory for guiding public health interventions; in DiClemente RJ, Crosby RA, Kegler MC (eds): Emerging Theories in Health Promotion Practice and Research: Strategies for Improving Public Health. San Francisco, Jossey Bass, 2002, pp 313-346.
12 Sikkema K, Heckman T, Kelly J, Anderson E, Winett R, Solomon L, et al: HIV risk behaviors among women living in low-income, inner-city housing developments. Am J Public Health 1996;86:1123-1128.

13 Wilson HM: Predictors of risky and precautionary sexual behaviors among single and married White women. J Appl Soc Psychol 2003;33:791.

14 El-Bassel N, Gilbert L, Witte S, Wu E, Chang M: Intimate partner violence and HIV among drug-involved women: contexts linking these two epidemics - challenges and implications for prevention and treatment. Subst Use Misuse 2011;46:295-306.

15 Hirsch J, Meneses S, Thompson B, Negroni M, Pelcastre B, del Rio C: The inevitability of infidelity: sexual reputation, social geographies, and marital HIV risk in rural Mexico. Am J Public Health 2007;97:986-996.

-16 Britton PJ, Levine OH, Jackson AP, Hobfoll SE, Sheperd JB, Lavin JP: Ambiguity of monogamy as a safer-sex goal among single, pregnant, inner-city women. J Health Psychol 1998;3:227-232.

17 DiClemente RJ, Crittenden CP, Rose E, Sales JM, Wingood GM, Crosby RA, et al: Psychosocial predictors of HIV-associated sexual behaviors and the efficacy of prevention interventions in adolescents at-risk for HIV infection: what works and what doesn't work? Psychosom Med 2008;70:598-605. 
18 Choi K, Catania J, Dolcini M: Extramarital sex and HIV risk behavior among US adults: results from the National AIDS Behavior Survey. Am J Public Health 1994;84:2003-2006.

19 Logan TK, Cole J, Leukefeld C: Women, sex, and HIV: social and contextual factors, metaanalysis of published interventions, and implications for practice and research. Psychol Bull 2002;128:851-885.

20 O'Leary A, Wingood G: Interventions for sexually active heterosexual women; in Peterson JL, DiClemente RJ (eds): Handbook of HIV Prevention. Abingdon, Taylor \& Francis, 2000, pp 179-197.

21 Braithwaite K, Thomas V: HIV/AIDS knowledge, attitudes, and risk-behaviors among African-American and Caribbean college women. Int J Adv Couns 2001;23:115-129.

22 Catania J, Coates T, Kegeles S: A test of the AIDS risk reduction model: psychosocial correlates of condom use in the Amen Cohort Survey. Health Psychol 1994;13:548-555.
23 Mishra S, Kumar B, Swain K: Sexual risk behaviour, knowledge and attitude related to HIV transmission: a study among a migrant tribal group living in the slums of Bhubaneswar City, Orissa, India. J Public Health 2008; 16:331-337.

24 Ho C, Loke A: HIV/AIDS knowledge and risk behaviour in Hong Kong Chinese pregnant women. J Adv Nurs 2003;43:238-245.

25 Bandura A: Social cognitive theory and exercise of control over HIV infection; in DiClemente RJ, Peterson J (eds): Preventing AIDS: Theories and Methods of Behavioral Interventions. New York, Plenum, 1994, pp 25-59.

26 Janz N, Becker M: The health belief model: a decade later. Health Educ Q 1984;11:1-47.

27 Hobfoll SE, Jackson AP, Lavin J, Britton PJ, Sheperd JB: Reducing inner-city women's AIDS risk activities: a study of single pregnant women. Health Psychol 1994;13:397-403.

28 Hobfoll SE: Grant Application: Women's Health Empowerment Project; unpublished manuscript, Kent, Kent State University, Department of Psychology, 2000.

29 Hobfoll SE, Jackson AP, Lavin J, Johnson RJ, Schröder KE: Effects and generalizability of communally oriented HIV-AIDS prevention versus general health promotion groups for single, inner-city women in urban clinics. J Consult Clin Psychol 2002;4:950-960.
30 Costa E, McIntyre T: Tradução e adaptação dos questionários do Women's Health Empowerement Project; unpublished manuscript, Porto, Departmento de Psicologia, Universidade Católica Portuguesa, 2002.

31 Hobfoll SE, Bansal A, Schurg R, Young S, Pierce CA, Hobfoll I, et al: The impact of perceived child physical and sexual abuse history on Native American women's psychological well-being and AIDS risk. J Consult Clin Psychol 2002;70:252-257.

32 Elifson K, Klein H, Sterk C: Religiosity and HIV risk behaviour involvement among "at risk" women. J Relig Health 2003;42:47-66.

33 Martín TC: Contraceptive use patterns among Spanish single youth. Eur J Contracept Reprod Health Care 2005;10:219-228.

34 Lagarde E, Caraël M, Glynn J, Kanhonou L, Abega S, Kahindo M, et al: Educational level is associated with condom use within nonspousal partnerships in four cities of SubSaharan Africa. AIDS 2001;15:1399-1408. 